\title{
The epistemic significance of modal factors
}

\author{
Lilith Newton ${ }^{1}$ \\ Received: 1 May 2019 / Accepted: 30 March 2020 / Published online: 9 April 2020 \\ (C) The Author(s) 2020
}

\begin{abstract}
This paper evaluates whether and to what extent modal constraints on knowledge or the semantics of 'knows', which make essential reference to what goes on in other possible worlds, can be considered non-epistemic factors with epistemic significance. This is best understood as the question whether modal factors are non-truth-relevant factors that make the difference between true belief and knowledge, or to whether a true belief falls under the extension of 'knowledge' in a context, where a factor is truth-relevant with respect to $\mathrm{S}$ 's belief that $\mathrm{P}$ iff it bears on the probability that $\mathrm{P}$ is true. To the extent that these factors are non-epistemic, epistemologies that endorse them-modal epistemologies - stand in conflict with intellectualism. I focus on three modal epistemologies: safety, sensitivity, and David Lewis's epistemic contextualism. I argue that prima facie, safety and sensitivity allow that non-epistemic changes in a context can shift the closeness ordering on worlds, and in so doing make a difference to whether S knows $\mathrm{P}$, while Lewis's contextualism allows that non-epistemic changes in a context can shift the relevant domain of not-P possibilities that must be eliminated for ' $\mathrm{S}$ knows $\mathrm{P}$ ' to be true in that context. Then to make her theory compatible with intellectualism, the modal epistemologist must say much more about the notion of probability at play in the definition of 'truth-relevant'. I suggest that either accepting or rejecting that modal epistemologies are intellectualist has significance consequences for debates between pragmatists and purists, which radiate into wider contemporary epistemology.
\end{abstract}

Keywords Intellectualism · Pragmatic encroachment · Modal epistemology · Safety · Epistemic contextualism $\cdot$ Counterfactual contextualism

Lilith Newton

lilith.newton@ed.ac.uk

1 University of Edinburgh, 3 Charles Street, Edinburgh EH8 9AD, UK 


\section{Introduction}

Certain theories of knowledge, or of the semantics of 'knowledge' and its cognates, claim that whether a subject $\mathrm{S}$ knows a proposition $\mathrm{P}$, or whether ' $\mathrm{S}$ knows $\mathrm{P}$ ' is true in a context, depends in some way on what goes on in other possible worlds. Call such views modal epistemologies. Modal epistemologies include safety and sensitivity theories, some forms of reliabilism, and relevant alternatives theories, such as David Lewis's epistemic contextualism. It is widely assumed that the modal constraints on knowledge, or 'knowledge', posited by these epistemologies are compatible with - and indeed support-purism, the view that practical considerations, such as what is at stake for $S$ in a context, do not bear on whether $S$ knows a given proposition, as well as intellectualism, the view that only factors that are appropriately 'truth-relevant' can make the difference between knowledge and mere true belief.

However, this claim has recently been called into question, with contextualism in particular being classified by some theorists as a pragmatist or practicalist epistemological position. Jonathan Adler, for example, classifies contextualism as practicalist, as the contextualist endorses his gloss on the thesis of pragmatic encroachment: "that specific changes in the costs or risks of error can alter standards for knowledge or for applying "knows"' (2012, p. 251, my emphasis), while Brian Kim holds that denying that contextualism is practicalist "makes less sense when one is contrasting it with the views of those who reject that the practical encroaches on knowledge in any way" (2017, pp. 9-10, fn. 8). Insofar as the practical factors that can make a difference to whether $\mathrm{S}$ knows $\mathrm{P}$, or whether it is true to say ' $\mathrm{S}$ knows $\mathrm{P}$ ' in a given context, are not appropriately truth-relevant, practicalism entails anti-intellectualism.

In this paper, I evaluate whether and to what extent the modal constraints on knowledge, or on 'knowledge', posited by these epistemologies can be considered non-epistemic factors with epistemic significance. As I will argue, this is the question whether and to what extent these are non-truth-relevant factors that can make the difference between mere true belief and knowledge, or to whether a true belief falls under the extension of 'knowledge' in a context. To the extent that these modal factors count as non-epistemic factors with epistemic significance, modal epistemologies stand in conflict with intellectualism. I focus my attention on safety and sensitivity theories, and Lewis's contextualism. I suggest in Sect. 3 that, prima facie, safety, sensitivity and Lewis's contextualism seem to allow that non-epistemic changes in a context can shift either the closeness ordering on worlds or the relevant domain of worlds, and in so doing make a difference to whether the posited constraint on knowledge, or 'knowledge', is satisfied, without making a difference to the probability that the proposition in question is true. But in Sect. 4 I argue that adopting a more sophisticated understanding of different notions of probability might allow the modal epistemologist to show that these modal shifts correspond to a difference in probability after all, hence vindicate the assumption that these epistemologies are intellectualist. In Sect. 5 I highlight some consequences of the preceding discussion for contemporary epistemology. But first, I begin in Sect. 2 by clearing up some conceptual confusion in the literature, through defining and distinguishing between key concepts at work in the debates between purists and practicalists, and intellectualists and anti-intellectualists. 


\section{The epistemic and the practical}

In order to evaluate whether and to what extent modal considerations should be thought of as non-epistemic factors with epistemic significance, we must first get clear on what is meant by 'epistemic' in each use in this sentence. In the introduction to his Knowledge and Practical Interests, Jason Stanley notes that "there are two senses in which epistemologists are prone to use the term 'epistemic'. On one use of 'epistemic', it denotes truth-conducive factors ... On the other understanding of 'epistemic', it has to do with factors relevant to whether a true belief is knowledge" (2005, p. 2). I take it that the use of 'epistemic' in the expression 'epistemic significance' is of this latter sense: a factor has epistemic significance iff it is relevant to whether a true belief is knowledge. But the use of 'epistemic' in 'non-epistemic factors' cannot also have this sense. If it did, there would be no question of whether non-epistemic factors can have epistemic significance, for by virtue of having epistemic significance-being relevant to whether a true belief is knowledge-they would count as epistemic after all. So the sense of 'epistemic' on which factors are classed as epistemic or non-epistemic must be the first sense that Stanley identifies: that of being 'truth-conducive'.

This use of 'epistemic' is commonplace in the literature on pragmatic encroachment. Stanley himself states that he will be '[u]sing 'epistemic' in the first of these ways" to advance the thesis that "what makes true belief into knowledge is not entirely an epistemic matter" (ibid.), while Jeremy Fantl and Matthew McGrath define "purely epistemic factors" as "factors that are appropriately "truth-related"” (2007, p. 558). From now on, when I use 'epistemic' I will mean it in the sense of being truthconducive, or truth-related. When I have occasion to use the word in the second sense, I will mark it with an asterisk: 'epistemic*'.

What it is for a factor to be truth-conducive or -related is standardly explicated in terms of probability. Stanley calls factors truth-conducive if "their existence makes the belief more likely to be true, either objectively or from the point of view of the subject" (2005, p. 1); Keith DeRose defines 'truth-relevant' factors as those that "affect how likely it is that the belief is true, either from the point of view of the subject or from a more objective vantage point" (2009, p. 24); Kim holds that "a factor is truth-relevant just in case it affects the likelihood that $\mathrm{p}$ is true or false" (2017, p. 1); and Blake Roeber writes that a factor is truth-relevant "just in case it affects the probability that your belief is true, either from your own point of view, or some more objective perspective" (2018a, p. 437). I shall say that a factor is epistemic iff it is truth-relevant, and that a factor is truth-relevant with respect to S's belief that $\mathrm{P}$ iff it affects the probability that $\mathrm{P}$ is true, either from S's point of view, or some more objective perspective.

The antonym of 'epistemic' is often given as 'practical'. Stanley contrasts epistemic factors with "practical facts", which are "facts about the costs of being right or wrong about one's beliefs" (2005, p. 6); Kim contrasts "truth-relevant factors" with "pragmatic factors" (2018, p. 69); and Michael Hannon calls equivalent the statements that "what counts as knowledge is independent of practical concerns" and that "whether a true belief amounts to knowledge depends only on purely epistemic factors-i.e., factors that are appropriately truth conducive" (2020 p. 690). But I wish to leave it open whether a non-epistemic factor with epistemic* significance must be related to such practical facts as what is at stake for a subject, hence I shall take 'non-epistemic' 
to be the antonym of 'epistemic', where a factor is non-epistemic just in case it does not bear on the probability that $\mathrm{P}$ is true, either from $\mathrm{S}$ 's point of view or from a more objective perspective. I shall call 'practical' factors those factors that have practical significance for a subject or attributor of knowledge: what is at stake, the practical purpose of ascribing knowledge in a case, and so on.

Pragmatic encroachment is the thesis that truth-irrelevant practical factors can have epistemic* significance. ${ }^{1}$ That is, practical factors, such as what is at stake for S, can make a difference to whether $\mathrm{S}$ knows that $\mathrm{P}$, without making a difference to the probability that $\mathrm{P}$ is true, either from $\mathrm{S}$ 's point of view, or some more objective perspective. ${ }^{2}$ Following Fantl and McGrath (2009), call purism the view that knowledge does not depend on truth-irrelevant changes in practical factors. The antithesis of purism, they call pragmatism: the view that truth-irrelevant practical factors can make a difference to whether S knows P. However as many theorists have noted, 'pragmatism' is something of an unsatisfying label for this view, as the term is strongly associated with the American pragmatist movement, and such thinkers as Dewey, James, and Peirce. For this reason, where I am not directly quoting from another philosopher, I will adopt Stephen Grimm's terminology, and call the view under which truth-irrelevant practical considerations can make a difference to knowledge practicalism (2011, p. 706).

Purism is true iff no possible pair of cases satisfies the following description: $S$ knows that $\mathrm{P}$ in Case $\mathrm{A} ; \mathrm{S}$ does not know that $\mathrm{P}$ in Case B; Case $\mathrm{A}$ and Case $\mathrm{B}$ are identical except for a difference in some truth-irrelevant practical factor. Call pairs of cases that satisfy this description 'encroachment cases'. Practicalism is true iff there exists at least one pair of encroachment cases. Thus, as Roeber notes, practicalism is "logically equivalent to an existential claim" (2018b, p. 3). The debate between purists and practicalists can be understood as a debate over the possibility of encroachment cases.

Practicalism is often taken to be implausible because it entails anti-intellectualism. ${ }^{4}$ Getting clear on the distinctions between purism and intellectualism, on the one hand, and practicalism and anti-intellectualism, on the other, will be important for what follows. Stanley calls 'intellectualism' the view that "knowledge does not depend on practical facts" (2005, p. 5) — the view I am here calling 'purism'. But others define 'intellectualism' without reference to practical factors, hence articulate it as a concept related to, but distinct from, purism. DeRose defines intellectualism as the view that

\footnotetext{
1 See for example Weatherson (2005, p. 417), Fantl and McGrath (2007, p. 559), Adler (2012, p. 247), $\operatorname{Kim}$ (2017, p. 1), Baril (2018, p. 56), Gerken (2018, p. 116). Jonathan Kvanvig is credited with coining the expression 'pragmatic encroachment'.

2 Pragmatic encroachment is sometimes defined as the thesis that truth-irrelevant factors can have epistemic* significance. See for example Nolfi (2018, p. 35). As I am distinguishing between 'practical' factors and 'non-epistemic' factors, I find such definitions unsatisfying. Nolfi's definition of pragmatic encroachment is better aligned with my gloss on 'anti-intellectualism', which is in line with that of Roeber (2018a).

3 See Grimm (2011, p. 706, fn. 4) and Roeber (2018c, p. 191, fn. 1).

4 Though some objections to practicalism centre on its allowing that practical factors, not truth-irrelevant factors in general, can make the difference to knowledge: see, for example, Russell and Doris's (2008) objection that practicalism seems to entail that, contrary to our strongly held normative judgements about knowledge, one can know more by caring less; or DeRose's objection from the implausibility of 'now you know it, now you don't' sentences such as "She does know, but she wouldn't have known if more had been at stake" (2009, p. 194-5).
} 
"the factors in virtue of which a true belief amounts to knowledge are exclusively truthrelevant" (2009, p. 24); Grimm that "[w]hether a true belief amounts to knowledge depends exclusively on truth-related factors" (2011, p. 706); and Roeber "that only truth-relevant factors can make the difference between knowledge and belief that falls short of knowledge" (2018a, p. 437-8).

As I do not take 'practical factors' to be the antonym of 'epistemic factors', I do not take intellectualism and purism to be equivalent theses. Rather, intellectualism entails purism, but not vice versa: if no truth-irrelevant factor can make a difference to knowledge (the intellectualist thesis), then no truth-irrelevant practical factor can make a difference to knowledge (the purist thesis). Conversely, practicalism entails anti-intellectualism, as Roeber notes: since truth-irrelevant practical factors can make a difference to knowledge, truth-irrelevant factors can make a difference to knowledge (2018a, p. 438).

The distinctions between purism and intellectualism, and between practicalism and anti-intellectualism, are subtle ones that often go unappreciated by those writing on the subject. Hannon, for example, defines purism as "the view that what counts as knowledge is independent of practical concerns. Put another way, whether a true belief amounts to knowledge depends only on purely epistemic factors-i.e., factors that are appropriately truth conducive" (2020, p. 690). Hannon's original statement of purism is unobjectionable. But what follows is not the same idea 'put another way', but rather the intellectualist thesis, which is stronger than purism.

Anti-intellectualism seems, on the face of it, to be highly implausible. Suppose you believe that Jupiter is the largest planet in our solar system, and compare two claims about your belief: first, that your belief cannot amount to knowledge unless it's based on good evidence that Jupiter is the largest planet in our solar system, and second, that it can't amount to knowledge unless you were born in January. The first claim is plausible, while the second is obviously false. As Roeber argues, we might naturally explain this difference in plausibility through appeal to the idea that only truth-relevant factors can make a difference to knowledge:

The evidence for your belief ..., the reliability of the cognitive faculties that produced this belief, and so on, all affect the probability that your belief is true-if not from your own point of view, then at least from some more objective perspective. In contrast, your [birth month] almost certainly does not affect the probability that your belief is true, from your perspective or any other. (2018a, p. 437).

The worry is that, if one follows the anti-intellectualist in denying that only truthrelevant factors can make the difference between mere true belief and knowledge, one is left with no principled way to exclude such obviously epistemically* insignificant factors as your birth month from playing a knowledge-affecting role in one's theory of knowledge. Hence epistemologists have resisted practicalism because it entails anti-intellectualism.

Philosophical lore has it that analytic epistemology is traditionally intellectualist. Fantl and McGrath call it "received tradition in analytic epistemology" that "whether a true belief qualifies as knowledge depends only on purely epistemic factors" (2007, p. 558). John Hawthorne describes his epistemological views as representing a break 
from orthodoxy because he holds that whether a true belief is knowledge depends on factors beyond those "traditionally adverted to in accounts of knowledge-whether the subject believes the proposition, whether the proposition is true, whether the subject has good evidence, whether the subject is using a reliable method, and so on" (2004, p. 158). And Mikkel Gerken writes that "strict purism", according to which "both knowledge itself and the semantics of 'knows' depend only on truth-relevant factors", is a central commitment of "orthodox epistemology" (2017, p. 15).

This narrative has been called into question, however. Grimm argues that many classical epistemologies allow that practical considerations can have epistemic* significance. He cites Locke's claim that "it is a very wrong and irrational way of proceeding, to venture a greater good for a less, upon uncertain guesses and before a due examination be made, proportionable to the weightiness of the matter, and the concernment it is to us not to mistake" $(1975,2.21 .66)$, arguing that Locke here suggests that "more is required for knowledge when the topic at hand is "weighty' than when it is not" (2015, p. 117). Hannon ascribes to Hume the belief "that we are pushed towards scepticism when reason acts 'alone,' that is, when the practical pressures to act and our natural inclination to believe what we see are suspended in the pursuit of reflective understanding" (2020, p. 691). Both Hannon and Grimm, following Bernard Williams (1978), attribute to Descartes the insight the we satisfy ourselves with less-than-certain beliefs in everyday life only because practical concerns require us to form beliefs and act on them.

So the narrative according to which traditional epistemology upholds intellectualism is not straightforwardly true. It certainly isn't the case that epistemologists have not, until the last fifteen years or so, grappled with practical considerations in developing their theories of knowledge. ${ }^{5}$ But we can accept the general point that much of analytic epistemology, especially post-Gettier, has been concerned with the articulation of necessary and sufficient conditions for knowledge that do not make reference to the practical situations of either the subject or the attributor of a knowledge claim. ${ }^{6}$ In this sense, analytic epistemology has traditionally been purist. Whether analytic epistemology has traditionally been intellectualist, on top of this, depends on whether the factors that epistemologists have taken to have epistemic* significance-whether a subject's evidence is sufficiently strong, whether her belief was formed through a reliable process, and so on-are all truth-relevant, in the sense of making a difference to the probability that the belief is true, either from the subject's own point of view, or a more objective perspective. In the next section, I will consider this question as applied to modal constraints on knowledge and on 'knowledge': constraints on which whether $\mathrm{S}$ knows that $\mathrm{P}$, or whether ' $\mathrm{S}$ knows $\mathrm{P}$ ' is true in a context, in the actual world depend in some way on what goes on in other possible worlds. I focus in particular on safety, sensitivity, and David Lewis's contextualism.

\footnotetext{
5 That practical considerations have played a significant role in many epistemologists' theories is even more obvious when we consider the pragmatist philosophies of Dewey, James, and Peirce.

6 See Stanley (2005, p. 1).
} 


\section{Modal constraints on knowledge}

Call a constraint on knowledge, or on 'knowledge', modal if it makes reference to what goes on in other possible worlds in determining whether $\mathrm{S}$ has knowledge, or whether it's true to say 'S knows P' in a context, in the actual world. Safety and sensitivity are modal constraints on knowledge. Safety says, roughly, that $\mathrm{S}$ knows that $\mathrm{P}$ only if $\mathrm{S}$ could not have easily come to falsely believe that $\mathrm{P}$, where this can be cashed out in terms of close possible worlds: S's belief that P is safe iff in all close worlds, S's counterpart does not falsely believe that P. Sensitivity says, again roughly, that $\mathrm{S}$ knows that $\mathrm{P}$ only if $\mathrm{S}$ would not have believed $\mathrm{P}$ had $\mathrm{P}$ been false, with this too standardly cashed out in the language of possible worlds: in the closest world in which not-P, S's counterpart does not believe that P.

It is standardly assumed that modal constraints on knowledge, or on the truth-value of 'knowledge'-ascriptions, are epistemic, hence that modal epistemologies are intellectualist. Fantl and McGrath write that "purely epistemic factors ... are appropriately 'truth-related.' If my true belief that p qualifies as knowledge while yours does not, this must be because of some difference in our evidence regarding $\mathrm{p}$, the reliability of the processes involved in our beliefs that $\mathrm{p}$, our counterfactual relations to the truth of p, and so on" (2007, p. 558, my emphasis); Grimm that "truth-connected factors [include] factors such as evidence, safety, and so on" (2011, p. 716); McGrath that epistemic factors include "externalistic factors such as how reliable one's p-relevant belief-producing processes are as well as how safe one's indications of p are" (2015, p. 141). If this is correct, then modal epistemologies are intellectualist.

Lewis's contextualism is a modal epistemology, on the definition given at the beginning of this paper, for it invokes modal considerations in explicating whether it is true to say ' $\mathrm{S}$ knows $\mathrm{P}$ ' in a given context $\mathrm{C}$. On Lewis's semantics for 'knows', it is true to say ' $\mathrm{S}$ knows $\mathrm{P}$ ' in $\mathrm{C}$ iff $\mathrm{S}$ 's evidence eliminates every not-P possibility in $\mathrm{C}$, where which possibilities fall under the domain of the quantifier 'every' is determined by context. Evidence eliminates a possibility, on Lewis's account, iff it is incompatible with that possibility: the possibility is one in which S's counterpart does not have the evidence that $\mathrm{S}$ has in the actual world (1996, p. 553).

Proponents of contextualism have argued that a key selling point of the theory lies in its ability to account for alleged encroachment cases while upholding intellectualism. DeRose writes that "[i]t is precisely because the contextualist holds fast to the intellectualist assumption that the truth of a given proposition ascribing knowledge to a subject cannot depend on practical, non-truth-relevant matters that he is led to posit that different knowledge relations are denoted in some of the cases in question" (2009, p. 25). That is, because the contextualist wants her account to be compatible with a theory of knowledge under which only truth-relevant factors have epistemic* significance, she posits a theory of 'knowledge' - the word and its cognates - under which 'knowledge' picks out different knowledge relations in different contexts, the instantiation of which is a matter of truth-relevant factors alone.

Recently, however, some epistemologists have argued that, insofar as contextualism allows that practical factors can make a difference in determining the content of 'knows', contextualism is an inherently practicalist position. Adler, for example, classes as practicalist any view under which "specific changes in the costs or risks of 
error can alter standards for knowledge or for applying 'knows' or other epistemic terms" (2012, p. 251, my emphasis), while Kim holds that denying that contextualism is a practicalist thesis "makes less sense when one is contrasting it with the views of those who reject that the practical encroaches on knowledge in any way" (2017, pp. 9-10, fn. 8). As practicalism entails anti-intellectualism, these theorists are committed to contextualism being an anti-intellectualist position, in contrast to what its proponents argue.

DeRose takes such classifications of contextualism to rest on a level confusion:

The contextualist does not hold that whether a subject knows or not can depend on non-truth-relevant factors: he holds that whether a speaker can truthfully describe the subject as 'knowing'... can depend on such factors. Whether the speaker can truthfully describe the subject as 'knowing' can depend on such factors, according to the contextualist, because such factors can affect the precise content of the speaker's claim, not because they can affect whether the subject is such as to make true the proposition that the speaker is asserting about her (2009, p. 188).

That is to say, contextualism itself is neither intellectualist nor anti-intellectualist, as (anti-)intellectualism is a thesis about knowledge, and contextualism a thesis about 'knowledge': the word and its cognates. Rather, contextualism will be consistent with intellectualism to the extent that a contextualist semantics for 'knows' can be correct while the intellectualist thesis is true. DeRose takes the contextualist semantics for 'knows' not only to be compatible with intellectualism, but to bolster support for the view, in explaining away apparent pairs of encroachment cases in intellectualistfriendly terms.

But if one is moved by Kim's suggestion that, when contrasting contextualism with traditional epistemological views on which both knowledge and the semantics for 'knows' are unaffected by practical considerations, it makes more sense to conceive of contextualism as a practicalist theory, one may be open to a similar suggestion regarding intellectualism. If one reason-maybe the primary reason-for classifying epistemological views as intellectualist or anti-intellectualist is to position them as in line with, or breaking from, epistemological orthodoxy, then there will be significant motivation for altering our understanding of intellectualism in such a way that views about the semantics for 'knows' are included as part of its subject matter.

For insofar as traditional epistemology has it that knowledge is affected only by epistemic factors, it holds that the same is true for the semantics of 'knows'. Gerken writes that epistemological orthodoxy is "strictly purist", in that it holds that "both knowledge itself and the semantics for 'knows' depend only on truth-relevant factors" (2017, p. 15). Given that 'truth-relevant', or 'epistemic', is not the antonym of 'practical', Gerken's 'strict purism' is better thought of as 'strict intellectualism', for purism is simply the denial that practical factors can make the difference between true belief and knowledge, and it remains to be seen whether there are non-epistemic factors that can make the difference that are not practical in the relevant sense-in particular, it might turn out that modal factors are non-epistemic without being practical. Similarly, Timothy Williamson writes that " $[\mathrm{t}]$ raditional epistemology ignores any indexicality in the word 'know'. It treats 'know' as having the same reference, and making the 
same contribution to what proposition is expressed by sentences in which it occurs, irrespective of the context in which the utterance is made" (2005, p. 215).

Then if the contextualist allows that non-epistemic factors can make the difference to whether a true belief falls under the extension of 'knowledge' in a context, her view will, at the very least in spirit, be in opposition to epistemological orthodoxy, which is intellectualist in a robust sense. I thus suggest that we differentiate between intellectualism as DeRose and Stanley conceive of it, and a more restrictive understanding of intellectualism, under which both knowledge and the semantics for 'knows' must be unaffected by non-epistemic factors in order for a position to count as intellectualist. Taking a hint from Gerken, I call these views 'moderate' and 'strict intellectualism', respectively:

Moderate intellectualism: Only epistemic (truth-relevant) factors can make the difference between true belief and knowledge.

Strict intellectualism: Only epistemic factors can make the difference between true belief and knowledge, or to whether a true belief falls under the extension of 'knowledge' in a given context of attribution.

DeRose's argument that to class contextualism as either intellectualist or antiintellectualist rests on a level confusion requires that 'intellectualism' is taken to pick out moderate intellectualism. But now it is clear that there is motivation for conceiving of intellectualism in the more restrictive sense, as strict intellectualism more comprehensively picks out the orthodox position in contemporary epistemology.

The more restrictive understanding of intellectualism necessitates an analogous restriction to our understanding of 'epistemic*'. Recall that I am using 'epistemic*' to pick out the second sense of 'epistemic' identified by Stanley, that of "[having] to do with factors relevant to whether a true belief is knowledge" (2005, p. 2). In line with the definition of 'strict intellectualism' offered here, we can redefine 'epistemic*' as 'having to do with factors relevant to whether a true belief is knowledge, or falls under the extension of "knowledge" in a given context'.

Note that moderate and strict intellectualism only come apart for epistemic contextualists: theorists who argue that sentences involving the word 'knows', or one of its cognates, are context-sensitive specifically due to the presence of this term. ${ }^{7}$ That is to say, epistemologists who take themselves to be invariantists about 'knows' and its cognates will likewise take themselves to be strict intellectualists iff they are moderate intellectualists. I wish to examine whether modal epistemologies should be thought of as anti-intellectualist, in either sense. It would be no surprise to find that Lewis's contextualism is moderately but not strictly intellectualist; recall that DeRose's contextualism sacrifices the view here called strict intellectualism in order to preserve the moderate intellectualism he endorses. But as safety and sensitivity theorists tend to take themselves to be invariantists about 'knows', 8 it would be an interesting result in itself to find that these views are moderately intellectualist but not strictly intellectu-

\footnotetext{
7 Thank you to Martin Smith for pointing this out to me.

8 Sensitivity theorist Nozick (1981) and proponents of safety Pritchard (2005), Sosa (1999) and Williamson (2000) all take themselves to be giving accounts of knowledge, not 'knowledge'. Pritchard explicitly positions safety as anti-contextualist, in that it "makes no mention of conversational contexts" (2005, p. 71), solving the problems that motivate contextualism with "no need for the attributor contextualist theoretical
} 
alist, as this would necessitate that these theorists accept some form of contextualism about 'knows' to coherently occupy this position. For now, the question remains open whether or not safety and sensitivity are intellectualist, in either sense.

I wish to examine whether modal epistemologies ought to be thought of as antiintellectualist on the basis of the 'shiftiness' of modality. In particular, I am concerned with whether the modal shifts, either in the set of possible worlds that are relevant in a context or in the relevant ordering on possible worlds, that are posited by these epistemologies to make the difference between true belief and knowledge, or to whether a true belief falls under the extension of 'knowledge' in a context, are plausibly thought of as epistemic factors. If they are not, then modal epistemologies are anti-intellectualist in at least one of the senses here identified, regardless of whether practical factors can make a difference to knowledge or to the application of 'knows' under a given modal epistemology. I consider first Lewis's contextualism, and second safety and sensitivity theories.

Under Lewis's contextualism, it is true to say ' $\mathrm{S}$ knows $\mathrm{P}$ ' in a context $\mathrm{C}$ iff S's evidence E eliminates every not-P possibility in C (1996, p. 551). E eliminates a possibility W iff $\mathrm{W}$ is a possibility in which S's counterpart does not have $\mathrm{E}$ (553). Which not-P possibilities fall under the domain of the quantifier 'every' is sensitive to the conversational context in which the attribution of knowledge is made. In any given context, a wide class of not-P possibilities are properly ignored, so do not fall under the domain of the quantifier 'every'.

Lewis posits a series of rules that determine whether a possibility is properly ignored in a context. The rule that does most of the work in explaining how the content of 'knows' shifts between contexts is his Rule of Attention':

When we say that a possibility is properly ignored, we mean exactly that; we do not mean that it could have been properly ignored. Accordingly, a possibility not ignored at all is ipso facto not properly ignored. What is and what is not being ignored is a feature of the particular conversational context. No matter how far-fetched a certain possibility may be, no matter how properly we might have ignored it in some other context, if in this context we are not in fact ignoring it but attending to it, then for us now it is a relevant alternative (1996, p. 559).

Put more succinctly: any possibility that is attended to in the current conversational context is not properly ignored in that context.

Lewisian contextualists can appeal to this rule to explain the differences in our willingness to ascribe knowledge in alleged encroachment cases, for example the Bank Cases. ${ }^{10}$ Consider the following pair of cases:

Case A: Hannah and her wife are driving home on a Friday afternoon. They plan to stop at the bank to deposit their paycheques, though it isn't important that

Footnote 8 continued

machinery" (75). Williamson argues that encroachment cases should be explained in terms of our desiring that subjects know that they know $\mathrm{P}$ in cases where there is much at stake regarding $\mathrm{P}$ (2005, pp. 230-33).

9 See for example Lewis's solution to the sceptical paradox (1996, p. 564).

10 The Bank Cases are originally due to DeRose (1992) and offered in support of contextualism. However Stanley (2005) argues that they better motivate his Interest Relevant Invariantism — a practicalist theory of knowledge. 
they do so today. As they drive past the bank, they notice that the lines inside are very long. Hannah says, "Why don't we come back tomorrow morning? I know the bank will be open-I was here two weeks ago on a Saturday. It's open until midday."

Case B: All is the same as in Case A, except Hannah and her wife have a very large mortgage payment due on Monday, and very little money in their account. If they do not deposit their cheques before Monday, there will not be enough money in their account to cover the payment, and they will default on their mortgage. Hannah again suggests they come back tomorrow morning, as she knows the bank will be open. But her wife reminds her how important it is that they deposit the cheques before Monday, and notes that banks do sometimes change their hours. Hannah says, "I guess you're right. I don't know that the bank will be open tomorrow morning. Let's deposit our cheques now."11

In Case A, where nothing much hangs on whether Hannah is right about the bank being open tomorrow morning, she counts as knowing that the bank will be open on the basis of having been there two weeks ago on Saturday morning. In Case B, however, we think that Hannah does not know the bank will be open on this same basis. The practicalist takes this pair of cases to support her theory: the only difference between Case A and Case B, she argues, is in the costs of Hannah's being mistaken about the bank being open; this practical difference is not truth-relevant, in that it doesn't bear on the probability that the bank will be open tomorrow; hence this is a pair of encroachment cases; hence practicalism is true.

The Lewisian contextualist can explain the difference in our willingness to ascribe knowledge between Cases A and B through appeal to the Rule of Attention. In Case A, we can suppose that Hannah's evidence eliminates every possibility in which the bank is closed tomorrow that is not properly ignored in this context, so it is true to say 'Hannah knows the bank will be open tomorrow'. The possibility that the bank has changed its hours is properly ignored. But in Case B, Hannah's wife bringing to her attention the possibility that the bank has changed its hours suffices for bringing this possibility under the domain of 'every', by the Rule of Attention. It is no longer properly ignored, so must be eliminated by Hannah's evidence in order for it to be true in this context to say 'Hannah knows the bank will be open tomorrow'. But Hannah's evidence, that she was at the bank two weeks ago on Saturday morning, does not eliminate the possibility that the bank has, since then, changed its hours. In order to eliminate this possibility, she must gather new evidence: she must, for example, go into the bank to ask a member of staff what its opening hours are. Thus in Case B, it is not true to say 'Hannah knows the bank will be open tomorrow'.

The Lewisian analysis of the Bank Cases is compatible with moderate intellectualism, as it says nothing about Hannah's knowledge, only about what she can truly be said to 'know' in a context. But is it compatible with strict intellectualism? It is a modal factor-which possible worlds are in the relevant domain - that makes the difference to whether Hannah's true belief falls under the extension of 'knowledge' between Cases A and B. There is a straightforward sense in which this modal factor has no bearing on the probability that Hannah's belief that the bank is open tomorrow

11 See DeRose (1992, p. 913) and Stanley (2005, pp. 4-5). 
is true. If we think of probabilities as features of the world, independent of any particular subject's evidence about or attitudes towards it, then while the probability that the bank is open tomorrow depends on whether the bank has changed its hours, it does not depend on whether Hannah's evidence is compatible with the possibility that the bank has changed its hours. Given this notion of probability, Lewis's contextualism is incompatible with strict intellectualism: it allows that truth-irrelevant factors can have epistemic* significance; that is, that factors that do not affect the probability that $\mathrm{P}$ is true can make the difference to whether one's true belief that $\mathrm{P}$ falls under the extension of 'knowledge' in a context.

This might not seem a surprising result. As noted, DeRose's contextualism was never meant to be compatible with the view here called strict intellectualism, but only with moderate intellectualism. Why, then, would we expect any different of Lewis's contextualism? However in the next section I will discuss a notion of probability under which Lewis's contextualism can be seen as strictly intellectualist. For now, I turn my attention to safety and sensitivity theories, and argue that, given the notion of probability currently under consideration, whether a belief that $\mathrm{P}$ is safe or sensitive can change due to a modal shift that doesn't bear on the probability that P. If safety or sensitivity is taken to be what makes the difference between true belief and knowledge, then whether $\mathrm{S}$ knows $\mathrm{P}$ can likewise change due to this modal shift, without a change in epistemic factors. I will first discuss safety and sensitivity given as counterfactual conditionals, and second safety given in terms of close worlds, or easy possibilities.

Safety says that $\mathrm{S}$ knows that $\mathrm{P}$ only if her belief that $\mathrm{P}$ is safe: $\mathrm{S}$ could not easily have come to falsely believe P. Proponents of safety include Ernest Sosa (1999), Williamson (2000) and Duncan Pritchard (2005). Sensitivity says that S knows that P only if her belief is sensitive: $\mathrm{S}$ would have not believed $\mathrm{P}$, had $\mathrm{P}$ been false. Proponents of sensitivity include Fred Dretske (1971) and Robert Nozick (1981), while Keith DeRose $(1995,2010)$ offers an 'indirect sensitivity' theory of knowledge, which appeals to the notion of sensitive belief in overcoming the sceptical challenge, without endorsing sensitivity as a necessary condition on knowledge.

Safety and sensitivity can be expressed as counterfactual conditionals:

Safety: If it were the case that $\mathrm{S}$ believed that $\mathrm{P}$, then $\mathrm{P}$ would be true $\left(\mathrm{B}_{\mathrm{S}} \mathrm{P}\right.$ $\square \rightarrow \mathrm{P}$ ).

Sensitivity: If $\mathrm{P}$ had been false, then $\mathrm{S}$ would not have believed that $\mathrm{P}(\sim \mathrm{P}$ $\square \rightarrow \sim \mathrm{B}_{\mathrm{S}} \mathrm{P}$ ).

The standard semantics for counterfactual conditionals is due to Robert Stalnaker (1968), Lewis (1973, 1979), and Angelika Kratzer (1977, 1981). Abstracting away from differences between their accounts, we can say that a counterfactual conditional 'If $\mathrm{P}$ were the case, then $\mathrm{Q}$ would be the case' is true at a world $\mathrm{W}$ iff all the closest $\mathrm{P}$-worlds to $\mathrm{W}$ are $\mathrm{Q}$-worlds. So the safety counterfactual tells us that in all the closest worlds in which $\mathrm{S}$ believes that $\mathrm{P}, \mathrm{P}$ is true, and the sensitivity counterfactual that in all the closest worlds in which $\sim \mathrm{P}, \mathrm{S}$ does not believe that $\mathrm{P}$.

But which worlds count as the closest P-worlds to $\mathrm{W}$ seems sometimes to be sensitive to contextual considerations, as Lewis notes: 
Counterfactuals are infected with vagueness, as everyone agrees. Different ways of (partly) resolving the vagueness are appropriate in different contexts. Remember the case of Caesar in Korea: had he been in command, would he have used the atom bomb? Or would he have used catapults? It is right to say either, though not to say both together. Each is true under a resolution of vagueness appropriate to some contexts (1979, p. 457).

Jonathan Ichikawa interprets Lewis as here endorsing a limited form of contextualism about counterfactuals, according to which " $[\mathrm{w}]$ hat notion of similarity is relevantly salient may change according to the conversational context; therefore, whether a counterfactual sentence is true depends not only on the antecedent, the consequent, and the state of the world, but also upon the conversational context" (2011, p. 293). This apparent context-sensitivity of counterfactuals is also noted by Stalnaker (1968, p. 109) and Kratzer (1981, p. 211).

Karen Lewis offers a minimal modification to the standard semantics for counterfactuals that captures this context-sensitivity. ${ }^{12}$ On her semantics, $\mathrm{P} \square \rightarrow \mathrm{Q}$ is true in a context $\mathrm{C}$ at a world $\mathrm{W}$ iff all the closest $\mathrm{P}$-worlds to $\mathrm{W}$ are $\mathrm{Q}$-worlds, but closeness is a function both of similarity to $\mathrm{W}$, and of relevance in $\mathrm{C}$ (2017, p. 416). A world is relevant if it is under consideration in a conversational context. Then the closeness ordering on worlds can shift due to what is under consideration in a conversational context: "worlds that are most similar might not be among the closest because they are simply not relevant to the conversation, and worlds that are not among the most similar might be among the closest because they are relevant in the context. Picturesquely speaking, relevance can take worlds that are among the most similar and move them further away, and take worlds that are less similar ... and move them to the closest sphere" (ibid.).

If we accept that counterfactual conditionals are context-sensitive in this way, then whether a belief satisfies the safety or sensitivity counterfactual can vary between contexts, due to a shift in the closeness ordering on worlds brought about by what is under consideration in those contexts. Returning to the Bank Cases, we can say that Hannah's belief in Case A is safe: had she believed that the bank is open tomorrow, her belief would be true, because in all close worlds in which Hannah's counterpart believes this, her belief is true. But in Case B, the world in which the bank has changed its hours is conversationally salient, hence relevant in the context, hence close. Now Hannah's belief is not safe, as it is not the case that, had she believed that the bank is open tomorrow, her belief would be true, because in one close world in which her counterpart believes this, her belief is false; namely, the possibility in which the bank has changed its hours. ${ }^{13}$

Similarly, we can say that Hannah's belief in Case A is sensitive, because had it been false that the bank is open tomorrow, she wouldn't have believed it. We can suppose, for example, that the closest world in which the bank isn't open tomorrow is one in which it wasn't open two weeks ago on Saturday either, hence a world in

\footnotetext{
12 Ichikawa (2011) offers a more substantial alteration of the standard semantics for counterfactuals, based on Lewis's (1996) rules for 'properly ignoring' possibilities in order to capture the context-sensitivity of counterfactuals.

${ }^{13}$ See also Ichikawa's (2011, p. 304) discussion of Sosa's (1999, p. 145-6) Trash Chute example.
} 
which Hannah's counterpart doesn't have the evidence that Hannah has in actuality, so doesn't believe that the bank will be open tomorrow. But in Case B, the world in which the bank has changed its hours has shifted to become the closest world in which the bank is open tomorrow. As Hannah's counterpart would believe that the bank is open in this world, Hannah's belief is not sensitive. Thus Hannah knows in Case A, but not in Case B.

It is more common to see safety explicated not using the counterfactual conditional, but instead simply in terms of close worlds, or easy possibilities. ${ }^{14}$ R. M. Sainsbury offers as a necessary condition on knowledge that "[if] you know, you couldn't easily have been wrong" (1997, p. 907), which he cashes out in the language of possible worlds: "It is easily possible for me to be wrong in believing that $\mathrm{P}$... iff at some world 'close' to the actual world the actual episode of forming the belief that $\mathrm{P}$ (or the counterpart of this episode) is one in which a false belief is formed" (913). In his earlier writings, Pritchard gives safety as the condition that "if an agent knows a contingent proposition $\phi$, then, in most nearby possible worlds in which she forms her belief about $\phi$ in the same way as she forms her belief in the actual world, that agent only believes that $\phi$ when $\phi$ is true" (2005, p. 157), and more recently as requiring no false belief in the "modal neighbourhood"- that is, the closest possible worlds (2015, p. 101).

On this understanding of safety, it will likewise be the case that, if it is allowed that closeness orderings on worlds can vary with what is under consideration in a conversational context, then whether a belief is safe will so vary. Returning to the Bank Cases, we can say that in Case A Hannah's belief is safe, as there are no close worlds in which her counterpart believes that the bank will be open tomorrow but her belief is false; in Case B, her belief is unsafe, as the world in which the bank has changed its hours is brought into the realm of the closest worlds due to her wife's bringing it up in conversation, and in this world, Hannah's counterpart falsely believes that the bank will be open tomorrow. If safety is what turns a true belief into knowledge, then Hannah knows that the bank will be open in Case A, and fails to know this in Case B.

Crucially, it is conversational salience that makes the difference to whether Hannah knows in these cases. Which possible worlds are conversationally salient does not affect the probability that Hannah's belief is true, on the notion of probability here under discussion: as a feature of the world, independent of any subject's evidence about or attitudes towards it. Then safety and sensitivity seem to allow that a non-epistemic factor can make the difference between whether or not a belief is safe or sensitive. If a true belief's being safe or sensitive is what makes it constitute knowledge, then a non-epistemic factor can make the difference between true belief and knowledge. Then safety and sensitivity are anti-intellectualist.

Significantly, this result does not depend on intellectualism being construed as strict intellectualism, as does the analogous result for Lewis's contextualism. It is not

\footnotetext{
14 A primary motivation for the move away from the counterfactual formulation of safety was the application of the problem of 'true/true' counterfactual conditionals to safety, which showed that, on anything like the standard semantics for counterfactuals, the safety counterfactual comes out true whenever $\mathrm{S}$ has a true belief that P. Then any true belief is safe and, if safety is what turns a true belief into knowledge, is knowledge too. DeRose puts the objection to Sosa's account of safety (2004, pp. 29-30), but before this Nozick had considered the problem as applied to his tracking theory of knowledge (1981, pp. 680-1, n. 8).
} 
simply the case that a shift in which possible worlds are close in a context makes the difference between whether or not 'Hannah knows that the bank is open tomorrow' can truly be said in that context. Rather, this modal shift makes the difference between her belief constituting knowledge or not. Hence safety and sensitivity will not be intellectualist on either construal of intellectualism, moderate or strict. This ought to surprise safety and sensitivity theorists. As noted at the start of this section, it is standardly assumed that modal constraints on knowledge are intellectualist. And it's likely this surprise would be an unpleasant one, at least for most safety and sensitivity theorists, who don't see their views as breaking significantly with epistemological orthodoxy in the same way that practicalists do. In the next section, I will explore one avenue for safety and sensitivity theorists, as well as Lewisian contextualists, to resist the classification of their views as anti-intellectualist: that of adopting a different notion of probability in their assessment of whether a factor is epistemic; specifically, a modal account of epistemic probability. Perhaps this will go some way to assuaging the modal epistemologist's discomfort with what she reads here.

\section{Probability and modal shifts}

It is standard to distinguish between objective and subjective probability. Though it is notoriously difficult to give a fully satisfying account of either notion, as a roughand-ready distinction, we can say that objective probabilities are features of the world, independent of our knowledge of, evidence about, or attitudes towards it, while subjective probabilities are relative to some subject(s) or body of evidence. If modal factors with epistemic* significance with respect to S's belief that $\mathrm{P}$ can always be shown to make a difference to either an objective or subjective probability that $\mathrm{P}$, then modal factors will count as epistemic factors, and modal epistemologies as intellectualist, on at least one of the senses of intellectualism discussed here.

Mellor distinguishes between three notions of probability: physical probability, also called 'chances', epistemic probability, and credences. Physical probabilities are features of the world, and are "neither relative to evidence nor mere matters of opinion" (2005, p. 8). For example, the chance that a radium atom will decay in a period of around 1600 years is 0.5 , and this would be so regardless of whether anyone knew anything about the half-life of radium. Epistemic probabilities measure whether and to what extent a given body of evidence confirms hypotheses about the world. They are thus essentially relative to a body of evidence. But as Mellor notes, they are not "mere matters of opinion: whether, and to what extent, evidence counts for or against a hypothesis looks like an objective matter" (ibid.). Finally, credences measure how strongly a subject believes a proposition. If $\mathrm{S}$ is maximally certain that $\mathrm{P}, \mathrm{S}$ 's credence in $\mathrm{P}$ is 1 ; if $\mathrm{S}$ is maximally certain that not-P, $\mathrm{S}$ 's credence in $\mathrm{P}$ is 0 ; and where $\mathrm{S}$ is neither certain that $\mathrm{P}$ or certain that not-P, S's credence in $\mathrm{P}$ lies somewhere between 0 and 1 . $\mathrm{S}$ 's credence in $\mathrm{P}$ need not be informed by any corresponding physical or epistemic probability that $\mathrm{P}$, though rationality demands that $\mathrm{S}$ tries to keep her credences in line with the epistemic probabilities of which she is aware.

On our rough-and-ready distinction between objective and subjective probabilities, physical probabilities are objective, while epistemic probabilities and credences are 
subjective. But it should be clear that the distinction is not quite as sharp as one might at first think. In particular, though both epistemic probability and credences are subjective, there is a sense in which epistemic probability is the more objective notion of the two: the epistemic probability that $\mathrm{P}$, given some body of evidence, is as it is regardless of whether any subject knows or believes it to be.

The notion of probability under which it is not plausible that modal factors affect probability is that of physical probability. The physical probability that $\mathrm{P}$, in the actual world, does not depend in any way on what goes on in other possible worlds, nor on which possible worlds are similar, relevant, and so on, to the actual world. Where 'probability' is taken to be physical probability - as it was in the previous sectionmodal epistemologies will allow that factors that do not affect the probability that $\mathrm{P}$ is true can make the difference between whether $\mathrm{S}$ knows or merely truly believes that $\mathrm{P}$, or to whether S's belief that $\mathrm{P}$ falls under the extension of 'knowledge' in a context. The question that remains, then, is whether modal considerations can make a difference to some subjective probability that $\mathrm{P}$. If any modal factor that makes the difference between mere true belief and knowledge, or a true belief falling under the extension of 'knowledge' in a context or not, can be shown to affect some subjective probability that $\mathrm{P}$, then modal epistemologies will be intellectualist.

It is obvious that modal considerations can affect credences. Reflecting on possibilities in which $\mathrm{P}$ is false may cause $\mathrm{S}$ 's credence in $\mathrm{P}$ to fall, while noticing that $\mathrm{P}$ holds in some wide class of possible worlds may cause it to rise. In this sense, modal factors can be truth-relevant. But this is not helpful for present purposes. To vindicate the assumption that modal epistemologies are intellectualist, it must be shown that a modal factor that makes the difference to whether a true belief is knowledge, or falls under the extension of 'knowledge', in any case can be shown to make a difference to the subjective probability that P. For any pair of alleged encroachment cases, the practicalist can simply stipulate that $\mathrm{S}$ does not change her credence in $\mathrm{P}^{15}$ Further, as Stanley points out, shifts in a subject's credences will be of no help in explaining pragmatic encroachment cases where only the attributor, and not the subject, of knowledge is aware of the high costs of being mistaken whether P (2005, p. 7).

To vindicate the assumption that modal epistemologies are intellectualist, then, it must be shown that the modal factors that make the difference between true belief and knowledge, or to whether a true belief falls under the extension of 'knowledge' in a context, always affect epistemic probability. And it is epistemic probability that pragmatic encroachment theorists tend to invoke in advancing their accounts. Stanley discusses "the epistemic probability of a proposition relative to the total evidence of an agent" (91, italicization removed), whereby "calling this notion epistemic, I mean to contrast it with subjective notions of probability, as well as more objective conceptions of probability, such as those involving the frequency in which an event would occur, given the ... evidence" (ibid.). Fantl and McGrath make use of the notion of "epistemic chance', which is contrasted with degrees of belief (credences), as well as objective chance: "whether it is rational to accept a gamble on $\mathrm{P}$ depends, not on your subjective

\footnotetext{
15 Indeed, in offering their alleged encroachment cases, practicalists tend to do just that; see for example Fantl and McGrath (2007, p. 560), or Roeber (2018c, p. 172).
} 
degree of belief, or on objective chances beyond your ken, but on how likely $\mathrm{P}$ is for you, i.e. on its epistemic chance" (2009, p. 13).

On the face of it, it may seem there can be no difference in the epistemic probability that S's belief is true between each case in a pair of alleged encroachment cases. For epistemic probabilities measure the extent to which a given body of evidence confirms a proposition, and it is crucial to the description of encroachment cases that the subject has the same evidence in both cases. Then the epistemic probability that S's belief is true ought to be the same in both cases: as her evidence is the same, her evidence should confirm the proposition believed to the same extent. If this is so, the modal epistemologist will be unable to appeal to epistemic probability to argue that wherever a change in a modal factor makes an epistemic* difference, there has been a change in the probability that S's belief is true, hence to argue that modal epistemologies are intellectualist.

However, I suggest there is a way of thinking about epistemic probability on which, although S's evidence is the same in both cases, the epistemic probability that $\mathrm{P}$, given S's evidence, differs between them. On this conception, the epistemic probability that $\mathrm{P}$ for $\mathrm{S}$ will be relative not only to $\mathrm{S}$ 's evidence, but further, to a set of possible worlds that are epistemically accessible for S-roughly, a set of worlds compatible with what $\mathrm{S}$ knows in the actual world (Kratzer 1991, p. 641). Which worlds are members of this set will then be posited to be partially determined by contextual considerations. The Lewisian contextualist could argue that worlds that are properly ignored in a context are not to be included in the set of worlds relative to which the epistemic probability that $\mathrm{P}$ is assessed; the safety or sensitivity theorist could argue that only close worlds are members of this set, and which worlds are close is, as Karen Lewis suggests, in part a matter of what is salient in a context.

What follows is not intended as a decisive argument that the modal epistemologies discussed in this paper are intellectualist, but rather one avenue for the modal epistemologist to explore if she is committed to showing her theory to be compatible with (at least moderate) intellectualism. Note, however that there is precedent for conceiving of epistemic probability in this way. To take two influential examples: Kratzer (1991, 2012) and Seth Yalcin (2010) offer incompatible analyses of epistemic probability, but both hold that epistemic probability is determined relative to a set of worlds that are epistemically accessible to $S$, and further, both allow that which worlds are included in this set might change depending on what is salient in a context (Kratzer 2012, pp. 98, 101; Yalcin 2010, p. 931).

Consider the notion of epistemic possibility suggested for the Lewisian contextualist as applied to her account of the Bank Cases. With 'P' standing for 'the bank is open tomorrow', the Lewisian holds that it is true to say 'Hannah knows P' in Case A, because her evidence eliminates every possibility in which not-P. In this context, the possibility that the bank has changed its hours is properly ignored, hence does not fall under the domain of 'every' not-P possibility. In Case B, it's false to say 'Hannah knows P', because Hannah's wife's utterance has brought the possibility that the bank has changed its hours into the domain of 'every' not-P possibility by the Rule of Attention, and Hannah's evidence does not eliminate this possibility.

But the proper ignoring that excludes the possibility in which the bank has changed its hours from the domain of 'every' not-P possibility in Case A also excludes it from 
the relevant set of worlds for evaluating the epistemic probability that P. Indeed, since every not-P possibility (with 'every' quantifying over only those possibilities that are not properly ignored) is eliminated by S's evidence in Case A, it is the case that every (again, with 'every' appropriately restricted) possibility epistemically accessible to $S$ is one in which P. Then S's evidence guarantees that P, in Case A, and the epistemic probability that $\mathrm{P}$, given $\mathrm{S}$ 's evidence, is 1 . However in Case B, as the possibility that the bank has changed its hours is not properly ignored, it is included in the set of worlds relative to which the epistemic probability that $\mathrm{P}$ is to be evaluated. As this is a world in which not-P, it is no longer the case that $\mathrm{S}$ 's evidence guarantees $\mathrm{P}$; hence in Case $\mathrm{B}$, the epistemic probability that $\mathrm{P}$ is $<1$. Then the epistemic probability that $\mathrm{P}$ is lower in Case B than in Case A, even though Hannah's evidence is the same in both cases. Thus there is an epistemic difference between the cases that tracks the difference in the truth value of 'Hannah knows P'. Strict intellectualism is preserved.

The safety or sensitivity theorist can similarly argue that her account of the Bank Cases is compatible with both moderate and strict intellectualism by holding that the set of worlds relative to which the epistemic probability that $\mathrm{P}$ is to be assessed is the set of closest epistemically accessible worlds, and that which worlds are closest can shift due to what is salient in a context. The safety theorist explains Hannah's knowing P in Case A and not in Case B by arguing that Hannah's belief that P is safe in the former case but not in the latter. In Case A, all close worlds in which Hannah's counterpart believes that $\mathrm{P}$ are $\mathrm{P}$-worlds. But in Case $\mathrm{B}$, the not-P world in which that the bank has changed its hours is one of the closest worlds in which Hannah's counterpart believes that $\mathrm{P}$. However, because the epistemic probability that $\mathrm{P}$ is to be assessed relative to the set of closest worlds, the safety theorist can hold that the epistemic probability that $\mathrm{P}$ is 1 in Case $\mathrm{A}$ and $<1$ in Case B: in Case A, but not Case $\mathrm{B}$, every world in the relevant set is a $\mathrm{P}$-world, hence $\mathrm{P}$ is guaranteed in Case $\mathrm{A}$, but not in Case B. Again, the difference in knowledge between Cases A and B corresponds to a difference in the epistemic probability that $\mathrm{P}$ between the cases. Moderate and strict intellectualism are preserved.

The sensitivity theorist can replicate this argument by adding the assumption that the closest not-P world in Case A is not epistemically accessible for Hannah. Plausibly, in Case A, the closest not-P world is one in which Hannah did not visit the bank two weeks ago on Saturday: the reason the bank isn't open tomorrow in this world is because it is never open on Saturdays. But this world isn't epistemically accessible to Hannah: it isn't compatible with all she knows in the actual world, for in the actual world she knows that she was at the bank two weeks ago on Saturday. Then the sensitivity theorist can argue that, in Case A, in all the closest epistemically accessible worlds, $\mathrm{P}$ is true, hence $\mathrm{P}$ has epistemic probability 1 in Case A. But in Case B, the (epistemically accessible) possibility that the bank has changed its hours is amongst the closest worlds, hence the epistemic probability that $\mathrm{P}$ is $<1$.

Accepting the argument of the previous section, that counterfactuals and closeness orderings on worlds are context-sensitive, would make the safety or sensitivity theorist a contextualist about 'knows'. To take safety as example: it could be the case that $\mathrm{S}$ knows $\mathrm{P}$ in a context $\mathrm{C}$, hence it is true to say ' $\mathrm{S}$ knows $\mathrm{P}$ ' in $\mathrm{C}$, because $\mathrm{S}$ 's belief is safe; but in another context $C^{\prime}$, in which a different closeness ordering on worlds is in effect due to differences in what is salient between $C$ and $C^{\prime}, S$ 's belief doesn't 
count as safe, hence it is false to say ' $\mathrm{S}$ knows $\mathrm{P}$ ' in $\mathrm{C}$ ', regarding the same $\mathrm{S}$ and the same P. Something like a contextualist safety theory is endorsed by DeRose (1995, 2004). But the question whether an epistemological view is contextualist, or requires contextualism about 'knows' for its coherence, is different to the question whether that view is intellectualist, in either sense. A theory can be both contextualist and strict intellectualist, provided that the contextual factors that can affect the truth-value of knowledge-attributions are always epistemic factors. If the safety or sensitivity theorist endorsed something like the view outlined in this section, she could posit that changes in the truth-value of knowledge-attributions between contexts will always be borne out in changes in the epistemic probability of the proposition in question. In this way, the contextualist safety theory that arises would be quite unlike DeRose's: strict intellectualism can be preserved, whereas DeRose sacrifices what is here called 'strict intellectualism', allowing that non-epistemic, and in particular practical facts, can bear on the meaning of 'knows' in a context.

The above can be read as a speculative proposal for one avenue the modal epistemologist could explore if she is committed to showing her view to be compatible with at least moderate intellectualism. Perhaps there are others. But it should now be clear that it can't be assumed that modal epistemologies are intellectualist, at least given the understanding of intellectualism as allowing only epistemic factors to make the difference between knowledge and true belief (the moderate intellectualist thesis), or between knowledge and true belief or to whether a true belief falls under the extension of 'knowledge' in a context (the strict intellectualist thesis). If 'epistemic' is taken to mean 'truth-relevant', which in turn is defined as 'affecting the probability that the relevant proposition is true, either from S's point of view, or some more objective perspective', then modal factors with epistemic* significance can be taken as epistemic factors only given much more fleshing out of the notion of probability these factors are meant to affect.

\section{A dilemma for contemporary epistemology}

In this section, I wish to draw attention to a further consequence of the preceding discussion. Given the context-sensitivity of modal terms, reflecting on modal epistemologies shows that at least one widely held assumption in contemporary epistemology must be false: either the assumption that supposed 'encroachment cases' cannot be explained in strict intellectualist-friendly terms, or the assumption that modal epistemologies are intellectualist. But to reject either claim has significant consequences for the current state of play in the debates over practicalism and purism, and intellectualism and antiintellectualism; consequences that may radiate into contemporary epistemology more generally. I will discuss each horn of this dilemma in turn.

The motivation for practicalism in epistemology requires that moderate intellectualism cannot account for supposed encroachment cases. Contextualists such as DeRose take these cases not to show that non-epistemic factors can make a difference to whether S knows P, but that such factors bear on what knowledge-relation 'knows' picks out in a context. Insofar as contextualist responses to encroachment cases are plausible, practicalism loses much of its bite. But at least something of epistemological 
orthodoxy has been conceded by the contextualist: whether it is true to say ' $\mathrm{S}$ knows $\mathrm{P}$ ' in a context can depend on non-epistemic factors, so strict intellectualism is false.

But what if these pairs of cases could be explained in such a way that is compatible even with strict intellectualism: the view that non-epistemic factors cannot make the difference to whether a true belief is knowledge, or falls under the extension of 'knowledge' in a given context? Allowing for the kind of context-sensitivity of modal terms discussed in Sect. 3, as well as endorsing an account of epistemic probability like those discussed in the last section, suggests that such a view is sustainable. In particular, one who endorses safety, sensitivity, or some other modal theory of knowledge can argue that alleged encroachment cases always involve a shift in how epistemically probable $\mathrm{P}$ is for $\mathrm{S}$, hence are not cases in which there is a difference in knowledge or the truth-value of 'S knows $\mathrm{P}$ ' without a difference in epistemic factors. Thus the entire epistemological orthodoxy can be preserved: neither knowledge, nor the semantics for 'knows', are affected by non-epistemic factors.

On the other hand, if the modal epistemologist does not want to adopt a view of epistemic probability like those outlined in the previous section, then she must make her own case for why her view is compatible with intellectualism, else the standard assumption that modal epistemologies are intellectualist must be abandoned. But to abandon this assumption would be to call into question the view on which post-Gettier epistemology is broadly intellectualist, and so to undermine arguments against practicalism that take the preservation of intellectualism to be of paramount importance to most contemporary epistemologists. ${ }^{16}$ For many influential post-Gettier theories of knowledge, even beyond those discussed this paper, make essential reference to what goes on in other possible worlds in determining what a subject knows in the actual world: Alvin Goldman's reliabilism, for example, requires for $\mathrm{S}$ to know that $\mathrm{P}$ that $\mathrm{S}$ can distinguish $\mathrm{P}$ in the actual world from some "relevant possible state of affairs in which P is false" (1976, p. 774), while John Greco's account of knowledge as success from ability explicates what it is for $\mathrm{S}$ to have an ability in terms of her having "a disposition or tendency to achieve [result] $\mathrm{R}$ across some range of relevantly close worlds" (2009, p. 22, Greco's emphasis). If some or all of these epistemologies are anti-intellectualist then, far from being the wildly implausible view many theorists have argued it to be, anti-intellectualism will be a central commitment of much contemporary epistemology. Then either accepting or rejecting the argument that modal factors always affect epistemic probability will have significant consequences for the pragmatic encroachment debate, which will likely resonate for contemporary epistemology more generally.

\section{Conclusion}

I hope to have shown in this paper that the question whether modal factors are nonepistemic factors with epistemic* significance is one which does not have a simple answer, and which deserves far greater exploration than it has yet been given. It has

\footnotetext{
16 Such an argument is central to DeRose's rejection of practicalist views in favour of his epistemic contextualism; see (2009, p. 189).
} 
been assumed by all writing on the subject that such modal constraints on knowledge as safety and sensitivity straightforwardly fall under the banner of 'intellectualism', but getting clearer on the definitions of 'intellectualism', 'epistemic', and so on, as well as on different notions of probability, has shown that work must be done in order for these modal factors to plausibly be understood as epistemic, hence these modal epistemologies as intellectualist. Finally, I hope to have shown that attempts to classify modal epistemologies as either intellectualist or anti-intellectualist raise significant questions for theorists on both sides of the pragmatic encroachment debate, questions which permeate contemporary epistemology more generally.

Open Access This article is licensed under a Creative Commons Attribution 4.0 International License, which permits use, sharing, adaptation, distribution and reproduction in any medium or format, as long as you give appropriate credit to the original author(s) and the source, provide a link to the Creative Commons licence, and indicate if changes were made. The images or other third party material in this article are included in the article's Creative Commons licence, unless indicated otherwise in a credit line to the material. If material is not included in the article's Creative Commons licence and your intended use is not permitted by statutory regulation or exceeds the permitted use, you will need to obtain permission directly from the copyright holder. To view a copy of this licence, visit http://creativecommons.org/licenses/by/4.0/.

\section{References}

Adler, J. E. (2012). Contextualism and fallibility: Pragmatic encroachment, possibility, and strength of epistemic position. Synthese, 188(2), 247-272.

Baril, A. (2018). Pragmatic encroachment and practical reasons. In B. Kim \& M. McGrath (Eds.), Pragmatic encroachment in epistemology. London: Routledge.

DeRose, K. (1992). Contextualism and knowledge attributions. Philosophy and Phenomenological Research, 52(4), 913-929.

DeRose, K. (1995). Solving the skeptical problem. The Philosophical Review, 104(1), 1-52.

DeRose, K. (2004). Sosa, safety, sensitivity, and sceptical hypotheses. In J. Greco (Ed.), Ernest Sosa and his critics. Oxford: Blackwell.

DeRose, K. (2009). The case for contextualism. Oxford: Oxford University Press.

DeRose, K. (2010). Insensitivity is back, baby! Philosophical Perspectives, 24(1), 161-187.

Dretske, F. (1971). Conclusive reasons. Australasian Journal of Philosophy, 49(1), 1-22.

Fantl, J., \& McGrath, M. (2007). On pragmatic encroachment in epistemology. Philosophy and Phenomenological Research, 75(3), 558-589.

Fantl, J., \& McGrath, M. (2009). Knowledge in an uncertain world. Oxford: Oxford University Press.

Gerken, M. (2017). On folk epistemology. Oxford: Oxford University Press.

Gerken, M. (2018). Pragmatic encroachment on scientific knowledge? In B. Kim \& M. McGrath (Eds.), Pragmatic encroachment in epistemology. London: Routledge.

Goldman, A. (1976). Discrimination and perceptual knowledge. The Journal of Philosophy, 73(20), $771-791$.

Greco, J. (2009). Knowledge as success from ability. Philosophical Studies, 142, 17-26.

Grimm, S. (2011). On intellectualism in epistemology. Mind, 120(479), 705-733.

Grimm, S. (2015). Knowledge, practical interests, and rising tides. In J. Greco \& D. K. Henderson (Eds.), Epistemic evaluation: Purposeful epistemology. Oxford: Oxford University Press.

Hannon, M. (2020). Why purists should be infallibilists. Philosophical Studies, 177(3), 689-704.

Hawthorne, J. (2004). Knowledge and lotteries. Oxford: Oxford University Press.

Ichikawa, J. (2011). Quantifiers, knowledge, and counterfactuals. Philosophy and Phenomenological Research, 82(2), 287-313.

Kim, B. (2017). Pragmatic encroachment in epistemology. Philosophy Compass. https://doi.org/10.1111/ phc3.12415.

Kim, B. (2018). An externalist decision theory for a pragmatic epistemology. In B. Kim \& M. McGrath (Eds.), Pragmatic encroachment in epistemology. London: Routledge. 
Kratzer, A. (1977). What 'must' and 'can' must and can mean. Linguistics and Philosophy, 1(3), 337-355.

Kratzer, A. (1981). Partition and revision: The semantics of counterfactuals. Journal of Philosophical Logic, 10(2), 201-216.

Kratzer, A. (1991). Modality. In A. von Stechow \& D. Wunderlich (Eds.), Handbook semantics. Berlin: de Gruyter.

Kratzer, A. (2012). Modals and conditionals. Oxford: Oxford University Press.

Lewis, D. (1973). Counterfactuals. Oxford: Blackwell.

Lewis, D. (1979). Counterfactual dependence and time's arrow. Noûs, 13(4), 455-476.

Lewis, D. (1996). Elusive knowledge. Australasian Journal of Philosophy, 74(4), 549-567.

Lewis, K. (2017). Counterfactuals and knowledge. In J. Ichikawa(Ed.), The Routledge handbook of epistemic contextualism. Oxford: Routledge.

Locke, J. (1975). An essay concerning human understanding. Oxford: Oxford University Press.

McGrath, M. (2015). Two purposes of knowledge-attribution and the contextualism debate. In J. Greco \& D. K. Henderson (Eds.), Epistemic evaluation: Purposeful epistemology. Oxford: Oxford University Press.

Mellor, D. H. (2005). Probability: A philosophical introduction. London: Routledge.

Nolfi, K. (2018). Another kind of pragmatic encroachment? In B. Kim \& M. McGrath (Eds.), Pragmatic encroachment in epistemology. London: Routledge.

Nozick, R. (1981). Philosophical explanations. Cambridge: Harvard University Press.

Pritchard, D. (2005). Epistemic luck. Oxford: Oxford University Press.

Pritchard, D. (2015). Anti-luck epistemology and the Gettier problem. Philosophical Studies, 172, 91-111.

Roeber, B. (2018a). Anti-intellectualism. Mind, 127(506), 437-466.

Roeber, B. (2018b). How to argue for pragmatic encroachment. Synthese. https://doi.org/10.1007/s11229018-1850-4.

Roeber, B. (2018c). The pragmatic encroachment debate. Nô̂s, 52(1), 171-195.

Russell, G., \& Doris, J. (2008). Knowledge by indifference. Australasian Journal of Philosophy, 86(3), 429-437.

Sainsbury, R. M. (1997). Easy possibilities. Philosophy and Phenomenological Research, 57(4), 907-919.

Sosa, E. (1999). How to defeat opposition to Moore. Philosophical Perspectives, 13, 141-153.

Stalnaker, R. (1968). A theory of conditionals. Studies in Logical Theory, American Philosophical Quarterly, 2, 41-55.

Stanley, J. (2005). Knowledge and practical interests. Oxford: Oxford University Press.

Weatherson, B. (2005). Can we do without pragmatic encroachment? Philosophical Perspectives, 19, 417-443.

Williams, B. (1978). Descartes: The project of pure enquiry. London: Routledge.

Williamson, T. (2000). Knowledge and its limits. Oxford: Oxford University Press.

Williamson, T. (2005). Contextualism, subject-sensitive invariantism and knowledge of knowledge. The Philosophical Quarterly, 55(219), 213-235.

Yalcin, S. (2010). Probability operators. Philosophy Compass, 5(11), 916-937.

Publisher's Note Springer Nature remains neutral with regard to jurisdictional claims in published maps and institutional affiliations. 